\title{
Combination Therapy of Inhaled Indacaterol/ Glycopyrronium for Chronic Obstructive Pulmonary Disease in the Very Elderly: Is It Safe? An Electrocardiographic Evaluation
}

\author{
Francesco Spannella ${ }^{a, b}$ Federico Giulietti ${ }^{a, b}$ Valentina Cesari ${ }^{a, b}$ \\ Antonio Francioso ${ }^{a}$ b Guido Cocci ${ }^{a}$, $b$ Laura Landi ${ }^{a} b \quad$ Francesca Elena Lombardi ${ }^{a}$ b

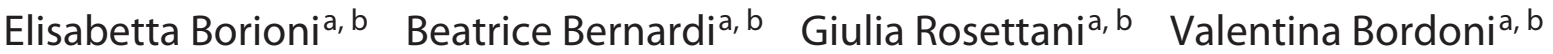 \\ Corrado lacoacci $^{a}$ Piero Giordano ${ }^{a}$ Riccardo Sarzani $^{a}$ b

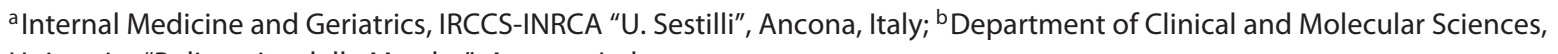 \\ University "Politecnica delle Marche", Ancona, Italy
}

\section{Keywords}

Indacaterol/glycopyrronium · Chronic obstructive

pulmonary disease $\cdot$ Elderly

\begin{abstract}
Cardiovascular (CV) comorbidities in patients with chronic obstructive pulmonary disease (COPD) are associated with increased morbidity and mortality, especially in old and very old subjects. The question if long-acting beta-agonist and long-acting muscarinic antagonist could be associated with the increased prevalence of CV-related adverse effects has puzzled, particularly in the past, specialists involved in the management of respiratory diseases. The safety of these compounds has scarcely been tested in patients aged $\geq 65$ years with CV comorbidities, since randomized controlled trials rarely include this subpopulation. However, the fixed combination indacaterol/glycopyrronium has shown a favorable CV safety profile in both healthy volunteers and COPD patients. Thus, we aimed to assess the $\mathrm{CV}$ safety profile of the fixed combination indacaterol/glycopyrronium $110 / 50 \mu \mathrm{g}$ in a series of COPD patients aged $\geq 80$ years with
\end{abstract}

(c) 2018 S. Karger AG, Basel

E-Mail karger@karger.com www.karger.com/res several comorbidities. Our results indicate that this combination is safe in the comorbid elderly, since no significant electrocardiographic abnormalities were recorded after the administration of the inhaled therapy. Only rare and nonclinically significant changes in heart rate and corrected QT interval duration were evident, mainly in females and in patients with concomitant impaired kidney function.

(c) 2018 S. Karger AG, Basel

\section{Introduction}

Chronic obstructive pulmonary disease (COPD) is a preventable and treatable disease characterized by a progressive decline in lung function, leading to high morbidity and mortality rates especially among the elderly [1]. It has been estimated that COPD will be the third cause of death worldwide by the year 2030. In the very elderly, COPD is often associated with several other comorbidities [2], mainly affecting the cardiovascular (CV) system, such as ischemic heart disease, heart failure and arrhythmias, cerebrovascular disease, and peripheral artery dis- 
ease [3]. Concomitant heart failure is an independent predictor of mortality in patients with COPD exacerbations [4], given the strong relationship between heart and lung. Pharmacological strategies in COPD patients aim to reduce the number and frequency of exacerbations and improve symptom control and exercise tolerance. Longacting muscarinic antagonists (LAMA) and/or long-acting $\beta_{2}$-agonists (LABA), with or without inhaled corticosteroids (ICS), are the treatments of choice for the chronic management of COPD patients, according to the Global Strategy for Diagnosis, Management and Prevention of COPD (GOLD 2017) [1].

Noteworthy, in the past, both LAMA and LABA have been associated with adverse $\mathrm{CV}$ effects and increased $\mathrm{CV}$ mortality $[5,6]$; however, newer and updated studies have, at least in part, reassured the safety of these compounds [7-9].

Despite some reassuring evidence, the CV safety of these drugs has not been well established in the very elderly, since only few retrospective data are available in people aged $\geq 65$ years $[10,11]$. For instance, very elderly patients are at an increased risk of developing conduction disturbances (i.e., QT prolongation, tachycardia and bradycardia, bundle branch block, and/or atrioventricular block), especially in the presence of comorbidities such as $\mathrm{CV}$ diseases or chronic kidney disease (CKD). This is further enhanced in the case of pharmacological treatments with multiple concomitant drugs for the management of comorbidities, due to possible interactions among molecules [12].

For these reasons, we assessed the CV safety of the indacaterol/glycopyrronium $110 / 50 \mu \mathrm{g}$ combination in a population of very elderly COPD patients admitted to our Internal Medicine and Geriatrics Unit, by evaluating electrocardiographic alterations following a single dose of this LABA/LAMA combination.

\section{Patients and Methods}

A total of 30 COPD patients aged $\geq 80$ years were recruited. They provided consent to the use of their data for research purposes, and the local Bioethics Committee approved this observation.

All the subjects evaluated had a history and/or a new diagnosis of COPD requiring inhaled bronchodilation with the indacaterol/ glycopyrronium combination, according to the GOLD 2017 criteria [1].

Patients were either naive to inhaled bronchodilatation therapy, or they needed a switch to the indacaterol/glycopyrronium combination from their previous treatment strategies as per clinical indication.

Indacaterol/Glycopyrronium for COPD in the Very Elderly
Several exclusion criteria were applied: presence of a cardiac pacemaker, permanent atrial fibrillation (AFib), pre-existing left bundle branch block, history of long QT syndrome or evidence of corrected QT interval (QTc) duration $>500 \mathrm{~ms}$ by the Fridericia formula $\left[\mathrm{QTc}=\mathrm{QT} /\left(\mathrm{RR}^{0.33}\right)\right]$, and psycho-physical conditions precluding the proper administration of inhaled therapy (i.e., insufficient peak inspiratory flow, difficulties using the device).

Several additional parameters were analyzed for safety reasons: hemoglobin levels, creatinine (its plasma concentration was determined with the "Jaffe" method, and glomerular filtration rate was estimated with the CKD-EPI equation) [17], sodium, potassium, and calcium levels, and arterial blood gas analysis.

All patients had been admitted to our clinic for worsening of clinical status. All evaluations were obtained after stabilization of the acute illness conditioning the hospital admission. We recorded 3 long-stripe ECG lasting $30 \mathrm{~s}$ each, immediately before (T0) as well as $15 \mathrm{~min}$ (T1) and $60 \mathrm{~min}$ (T2) after the first administration of the indacaterol/glycopyrronium combination, according to the pharmacokinetic properties of the two drugs, which reach peak plasma concentrations (Cmax) 15 min after inhalation [13]. ECG were evaluated for QTc duration, PR and QRS interval duration, heart rate (HR), and presence of arrhythmias or either supraventricular or ventricular ectopic beats.

Moreover, arterial blood pressure, HR, and pulse-oximetry were measured at the same time intervals.

Our group used the following definitions to classify patients: dyslipidemia $=$ total cholesterol levels $\geq 200 \mathrm{mg} / \mathrm{dL}$ and/or use of lipid-lowering drugs; renal impairment $=$ eGFR $<60 \mathrm{~mL} / \mathrm{min} /$ $1.73 \mathrm{~m}^{2}$; anemia $=$ hemoglobin $<12 \mathrm{~g} / \mathrm{dL}$; polypharmacotherapy $=$ more than 5 concomitant drugs in each single patient.

\section{Statistical Analysis}

Statistical analysis was performed with the SPSS software (Version 13 for Windows; SPSS Inc., Chicago, IL, USA). Data were expressed as means \pm standard deviation for normal distribution variables and as medians (interquartile range) for non-normal distributions. A $p$ value $<0.05$ was considered statistically significant.

Analysis of variance (ANOVA), analysis of co-variance (ANCOVA), McNeman test, Friedman test, and the two-sided test marginal homogeneity were used to assess the differences of the selected variables at the specified time intervals T0, T1, and T2.

\section{Results}

The baseline characteristics of the enrolled patients are shown in Table 1. A slight majority of patients were females $(56.7 \%)$, with a mean age of $86.5 \pm 4.6$ years. The most frequently used CV drugs were beta-blockers (65.2\%), ACE-inhibitors/ARBs (78.3\%), diuretics (65.2\%), digoxin (4.3\%), lipid-lowering drugs (20.0\%), and antiplatelet/antithrombotic agents (63.3\%).

At T0, the mean systolic blood pressure was $121.6 \pm$ $24.0 \mathrm{~mm} \mathrm{Hg}$, the mean diastolic blood pressure was 67.6 $\pm 13.4 \mathrm{~mm} \mathrm{Hg}$, and the mean HR was $76.7 \pm 16.7 \mathrm{bpm}$. 
Table 1. Baseline (T0) characteristics of the population

\begin{tabular}{lc}
\hline Demographic variables & \\
Age, years & $86.5 \pm 4.6$ \\
Female gender & $17(56.7)$ \\
Smokers & $25(84)$ \\
Polypharmacotherapy & $25(83.3)$ \\
Type 2 diabetes mellitus & $7(23.3)$ \\
Dyslipidemia & $11(39.3)$ \\
Arterial hypertension & $24(80.0)$ \\
Anemia & $13(43.3)$ \\
Chronic kidney disease & $9(30)$ \\
Heart failure & $17(58.6)$ \\
Peripheral artery disease & $17(58.6)$ \\
Previous stroke/transient ischemic attack & $5(16.7)$ \\
Previous coronary artery disease & $7(24.1)$ \\
Paroxysmal AFib & $12(40.0)$ \\
\hline Laboratory parameters & \\
Hb, g/dL & $12.2 \pm 2.0$ \\
Creatinine, mg/dL & $1.0 \pm 0.4$ \\
eGFR, mL/min/1.73 m ${ }^{2}$ & $61.1 \pm 19.6$ \\
Sodium, mEq/L & $139.7 \pm 3.8$ \\
Potassium, mEq/L & $4.3 \pm 0.5$ \\
Calcium, mg/dL & $8.8 \pm 0.8$ \\
\hline Arterial blood gas analysis & \\
pH $_{\text {pO }}$, mm Hg & $7.45 \pm 0.04$ \\
pCO $_{2,}$ mm Hg & $62.1 \pm 10.0$ \\
HCO ${ }^{-}$, mEq/L & $45.7 \pm 6.9$ \\
\hline & $31.2 \pm 4.5$ \\
\hline & $94.7 \pm 2.8$ \\
\hline
\end{tabular}

Continuous variables are expressed as means \pm standard deviation. Categorical variables are expressed as absolute numbers and percentages. AFib, atrial fibrillation; Hb, hemoglobin; eGFR, estimated glomerular filtration rate.

No variations in blood pressure levels and HR were noted over time (Fig. 1a, b).

All patients were in sinus rhythm at T0 and no arrhythmias were registered at both $\mathrm{T} 1$ and $\mathrm{T} 2$. The mean QTc interval duration was $428.9 \pm 40.1 \mathrm{~ms}$, the mean PR duration was $174.5 \pm 39.6 \mathrm{~ms}$, and the mean QRS duration was $100.3 \pm 29.6 \mathrm{~ms}$. The interval durations were constant over time (Fig. 2). At T1, 1 male and 1 female patient presented a transient prolongation of the QTc interval above normal reference values (QTc $<450 \mathrm{~ms}$ for men and $<470 \mathrm{~ms}$ for women), with values of 474 and 509 $\mathrm{ms}$, respectively. In both cases, the QTc interval returned to normal values at $\mathrm{T} 2$, none of them had an increase of greater than $60 \mathrm{~ms}$, and neither patient presented QTc prolongation after $60 \mathrm{~min}$ of indacaterol/glycopyrronium administration.
Single supraventricular or ventricular ectopic beats were present in 11 patients at T0; the prevalence of ectopic beats remained stable after indacaterol/glycopyrronium administration, with 9 and 10 patients showing $1 \mathrm{ec}-$ topic beat at $\mathrm{T} 1$ and $\mathrm{T} 2$, respectively. The administration of the LABA/LAMA combination therapy did not result in any new-onset arrhythmias.

We additionally analyzed the effects of several independent parameters on HR and QTc interval duration after administration of the combined inhalation therapy. The parameters evaluated were gender, anemic state, presence of heart failure signs and symptoms, CKD, paroxysmal AFib, and concomitant use of beta-blockers. Among females, a statistically significant reduction in HR at T2 versus T0 was documented ( $p=0.014)$, whereas HR remained stable in males (Fig. 3). QTc duration was longer in females at T0 as compared to male patients $(p=$ 0.046 ), but the difference disappeared at both T1 and T2 (Fig. 4).

A slight prolongation in the QTc interval duration was found in patients with CKD between T1 and T2 (Fig. 5), although not statistically significant.

Hematic concentrations of the main electrolytes analyzed (sodium, potassium, and calcium) did not appear to influence HR variability or QTc interval duration (all $p=\mathrm{ns})$.

\section{Discussion}

An increasing number of elderly patients need hospitalization for COPD exacerbation, with 90-day mortality rates 3 -fold higher than in younger patients [14]. The majority of these deaths are related to $\mathrm{CV}$ comorbidities in COPD patients [15]. Of note, recent studies from our group demonstrated the high prevalence of heart failure in very elderly patients admitted to hospital for COPD, as well as the important role of CV therapies in this subgroup of patients $[16,17]$. However, these very high-risk populations are scarcely represented in randomized controlled trials, with scarce evidence available on the safety and tolerability of pharmacological therapies in this particular population [18].

The negative impact of COPD on the CV system may depend on several factors: the commonly shared risk factors, such as cigarette smoking, sedentary lifestyle, and the chronic proinflammatory state with subsequent microcirculation disturbances $[19,20]$.

LABA and LAMA represent the mainstay of inhaled bronchodilation therapy, with a strong positive impact
Spannella et al. 
Fig. 1. Arterial blood pressure (BP) (a) and heart rate $(\mathbf{b})$ variability after a single dose of indacaterol/glycopyrronium.

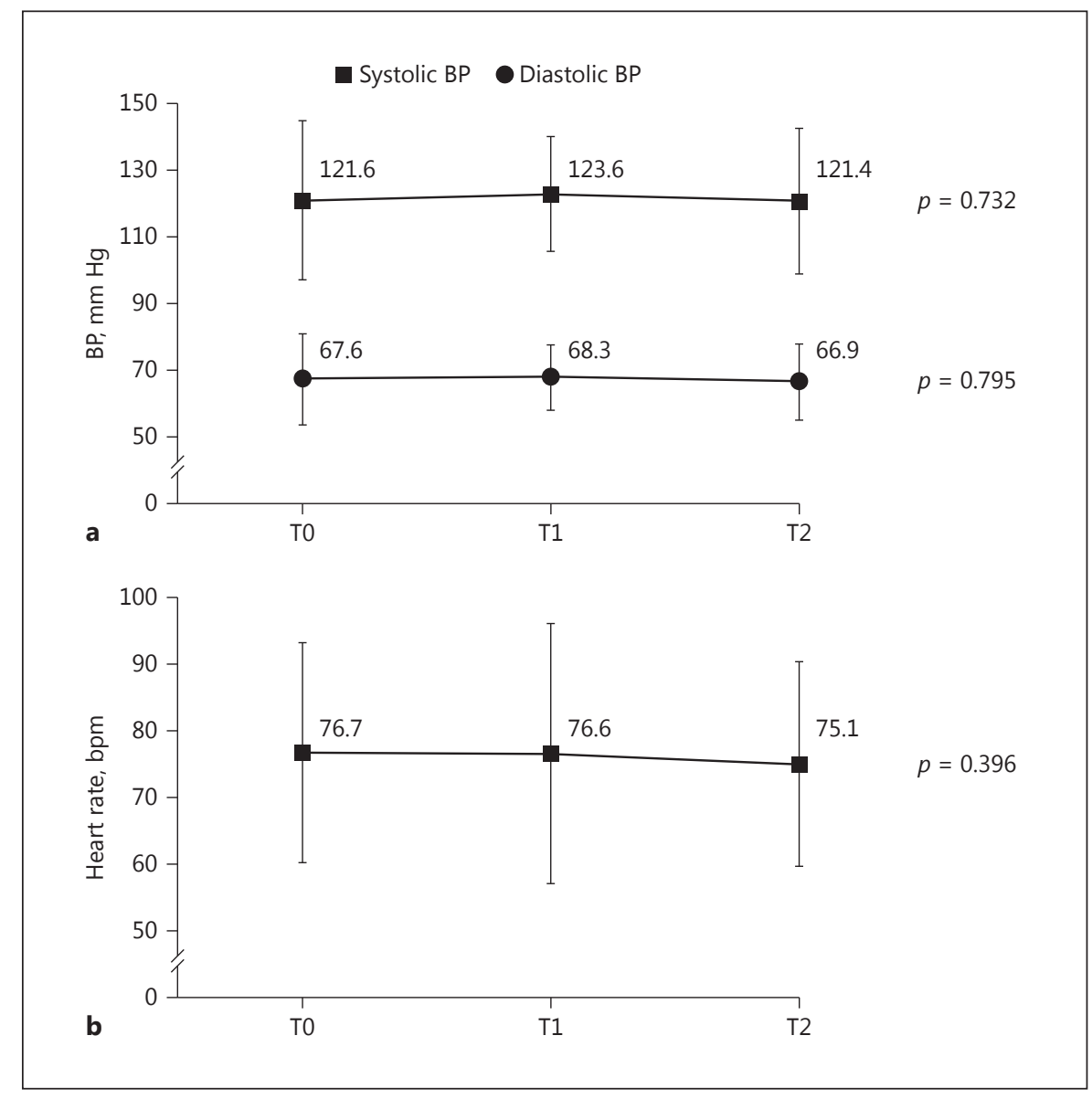

on quality of life and number of exacerbations [21]. In Italy, tiotropium, glycopyrronium, umeclidinium, and aclidinium are the approved LAMA for COPD chronic management, whereas vilanterol, indacaterol, olodaterol, formoterol, and salmeterol are the approved LABA. All these drugs can be used alone or in combinations, since the fixed compound combination exerts a synergic effect on patients' obstructed airways maximizing bronchodilation [22].

Although the population is aging and many elderly patients present with both COPD and CV comorbidities, scarce evidence is available regarding the safety of the newer LABA/LAMA combination drugs in this group of patients [22]. A large observational population-based study investigating patients with a mean age of $79.0 \pm 7.1$ years has recently revealed an increased CV-related hospitalization rate in patients treated with LABA and/or LAMA, independent from the pharmacological drug class used [6]. Other evidence points to a good safety profile of LABA/LAMA combination in COPD patients [9].
In our experience, we did not register significant variations in HR and QTc, PR, and QRS intervals from baseline to both 15 and $60 \mathrm{~min}$ after the administration of a single indacaterol/glycopyrronium 110/50 $\mu \mathrm{g}$ dose, in a population of very elderly with multiple comorbidities.

QT prolongation is a surrogate marker of proarrhythmic risk of non-anti-arrhythmic drugs; moreover, COPD exacerbations with respiratory failure are an independent predictor of arrhythmias [23, 24]. Of note, the increased prevalence of comorbidities in the elderly is linked to prolonged hospitalization and worse in-hospital mortality in patients aged $>73$ years [2]. In young healthy volunteers, glycopyrronium showed a very safe profile regarding QTc interval modifications, even at higher than therapeutical doses, compared with placebo [13]. Similar findings were also obtained in the GLOW 1 study, in which none of the patients developed a QTc prolongation of $>500 \mathrm{~ms}$ [25]. A recent paper on indacaterol safety in COPD patients aged $\geq 65$ years [26] concluded that incidences of adverse events among indacaterol- or placebo-treated patients 
Fig. 2. $Q T c(\mathbf{a}), P R(\mathbf{b})$, and $Q R S(\mathbf{c})$ interval duration variability after a single dose of indacaterol/glycopyrronium.

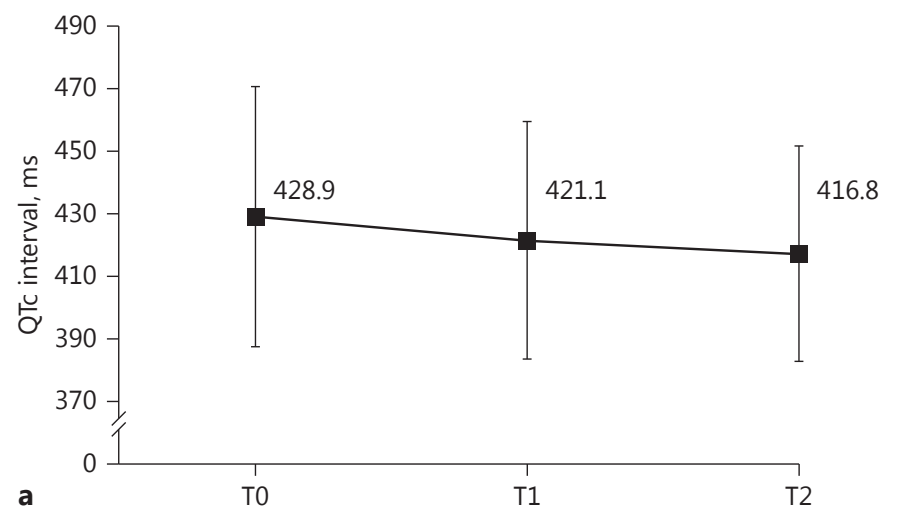

$p=0.196$

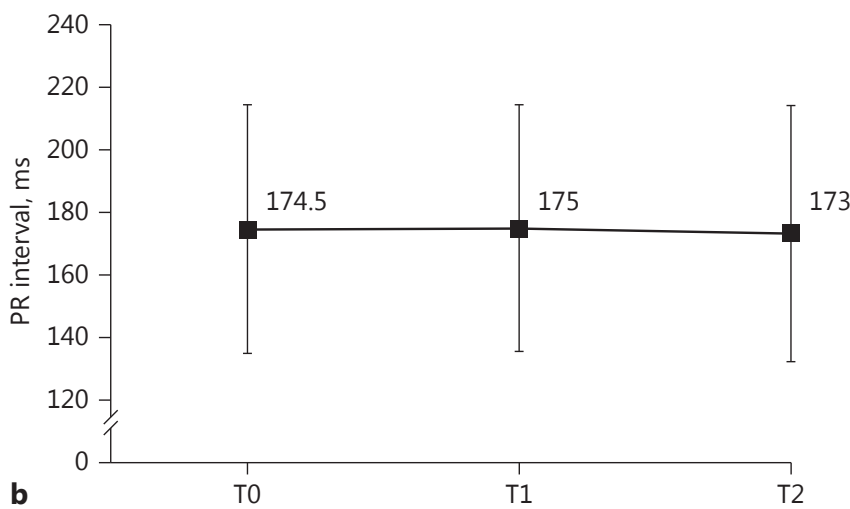

$p=0.870$

$p=0.116$

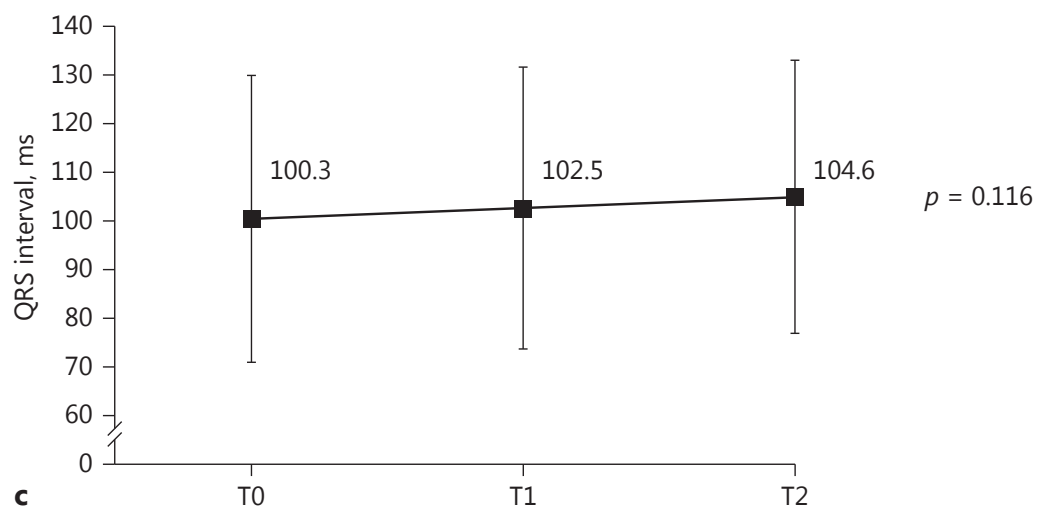

were similar, regardless of the age group. Moreover, patients treated with the indacaterol/glycopyrronium combination in the SHINE study did not experience any CV event, without significant differences in QTC interval duration and AFib incidence versus both single pharmacological agents and placebo over a 26 -week follow-up period [27].

We also evaluated the independent effect of several variables on the variability of HR and QTC interval dura- tion: a slightly gender-related difference in HR was noted, although not statistically significant; regarding the QTc interval, only the presence of CKD might influence its duration, with a transient prolongation of the QTc interval at T1 and T2 in patients with versus patients without CKD. We do not know the true reason behind this finding, a causal effect was not proven, a possibility for a chance finding could be taken into account. At present, there are no requirements for dose adjustment or contra- 
Fig. 3. Gender-dependent variability in heart rate.

Fig. 4. Gender-dependent QTc interval duration variability.

Fig. 5. Chronic kidney disease (CKD)-related QTc interval prolongation.
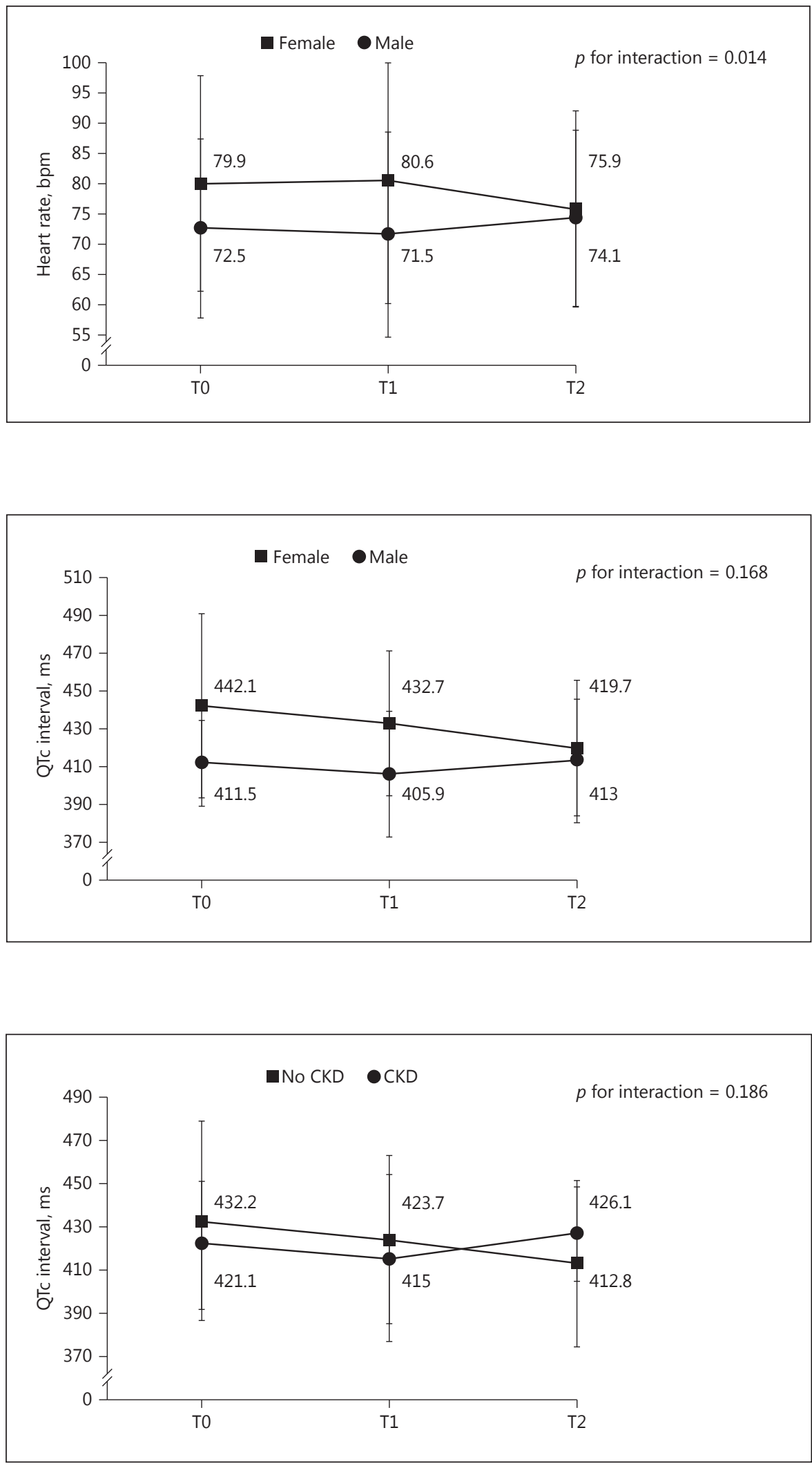

Indacaterol/Glycopyrronium for COPD in the Very Elderly 
indications for indacaterol/glycopyrronium use in COPD patients with mild-to-moderate CKD or more than 75 years old.

Of note, we evaluated very old patients from a "reallife" setting, usually not represented in clinical trials. However, our analysis presents several limitations. First of all, a relatively low number of patients was observed. Secondly, the single ECG recordings at different times do not inform about rhythm alterations during prolonged periods, and thus 24 -h ECG-Holter monitoring should be necessary.

\section{Conclusion}

The CV safety of LABA and LAMA and their combination is still debated. We showed that the indacaterol/ glycopyrronium $110 / 50 \mu \mathrm{g}$ combination is associated with a good cardiac safety profile in the very elderly with multiple comorbidities, in terms of short-term proarrhythmic risk after a single dose of this compound combination.

Our data offer new insights on this issue, and further studies may in the future assess the CV safety profile of bronchodilation therapies in larger groups of elderly patients over the medium-long period.

\section{Acknowledgement}

The authors thank Luca Giacomelli, $\mathrm{PhD}$, for providing medical writing on behalf of Content $\mathrm{Ed} \mathrm{Net}$; this assistance was funded by Novartis Farma SpA.

\section{Financial Disclosure and Conflicts of Interest}

The authors have no conflicts of interest directly relevant to this study.

\section{References}

1 Global Initiative for Chronic Obstructive Lung Disease (GOLD 2017): Global Strategy for the Diagnosis, Management and Prevention of Chronic Obstructive Pulmonary Disease. Updated 2017. www.goldcopd.org.

2 Baty F, Putora PM, Isenring B, Blum $\mathrm{T}$, Brutsche M: Comorbidities and burden of COPD: a population based case-control study. PLoS One 2013;8:e63285.

3 De Lucas-Ramos P, Izquierdo-Alonso JL, Rodriguez-Gonzalez Moro JM, Frances JF, Lozano PV, Bellón-Cano JM; CONSISTE study group: Chronic obstructive pulmonary disease as a cardiovascular risk factor. Results of a case-control study (CONSISTE study). Int J Chron Obstruct Pulmon Dis 2012;7:679-686.

4 Slenter RHJ, Sprooten RT, Kotz D, Wesseling G, Wouters EF, Rohde GG: Predictors of 1-year mortality at hospital admission for acute exacerbations of chronic obstructive pulmonary disease. Respiration 2013;85:1526

5 Singh S, Loke YK, Furberg CD: Inhaled anticholinergics and risk of major adverse cardiovascular events in patients with chronic obstructive pulmonary disease. JAMA 2008;300: 1439-1450.

6 Gershon A, Croxford R, Calzavara A, To T, Stanbrook MB, Upshur R, Stukel TA: Cardiovascular safety of inhaled long-acting bronchodilators in individuals with chronic obstructive pulmonary disease. JAMA Intern Med 2013;173:1175-1185.
7 Scott DA, Woods B, Thompson JC, Clark JF, Hawkins N, Chambers M, Celli BR, Calverley $\mathrm{P}$ : Mortality and drug therapy in patients with chronic obstructive pulmonary disease: a network meta-analysis. BMC Pulmonary Medicine 2015;15:145.

8 Wise RA, Anzueto A, Cotton D, Dahl R, Devins T, Disse B, Dusser D, Joseph E, Kattenbeck S, Koenen-Bergmann M, Pledger G, Calverley P; TIOSPIR Investigators: Tiotropium respimat inhaler and the risk of death in COPD. N Engl J Med 2013;369:1491-1501.

9 Samp JC, Joo MJ, Schumock GT, Calip GS, Pickard AS, Lee TA: Risk of cardiovascular and cerebrovascular events in COPD patients treated with long-acting $\beta$ 2-agonist combined with a long-acting muscarinic or inhaled corticosteroid. Ann Pharmacother 2017;51:945-953.

10 Wilchesky M, Ernst P, Brophy JM, Platt RW, Suissa S: Bronchodilator use and the risk of arrhythmia in COPD: part 1: Saskatchewan cohort study. Chest 2012;142:298-304.

11 Wilchesky M, Ernst P, Brophy JM, Platt RW, Suissa S: Bronchodilator use and the risk of arrhythmia in COPD: part 2: reassessment in the larger Quebec cohort. Chest 2012;142: 305-311.

12 Mizokami F, Koide Y, Noro T, Furuta K: Polypharmacy with common diseases in hospitalized elderly patients. Am J Geriatr Pharmacother 2012;10:123-128.
13 Drollmann A, Sechaud R, Pal P, Hara H, Uziel-Fusi S, Winkle P: Glycopyrronium does not affect QT interval in healthy subjects: a randomized, three-period, cross-over, placebo- and positive-controlled study. Int J Clin Pharmacol Ther 2014;52:739-745.

14 Connolly MJ, Lowe D, Anstey K, Hosker HS, Pearson MG, Roberts CM; British Thoracic Society and the Royal College of Physicians Clinical Effectiveness Evaluation Unit (CEEu): Admissions to hospital with exacerbations of chronic obstructive pulmonary disease: effect of age related factors and service organisation. Thorax 2006;61:843-848.

15 Anthonisen NR, Skeans MA, Wise RA, Manfreda J, Kanner RE, Connett JE; Lung Health Study Research Group: The effects of a smoking cessation intervention on 14.5-year mortality: a randomized clinical trial. Ann Intern Med 2005;142:233-239.

16 Spannella F, Giulietti F, Balietti P, Cocci G, Landi L, Lombardi FE, Borioni E, Bernardi B, Rosettani G, Bordoni V, Sarzani R: Renin-angiotensin system blockers and statins are associated with lower in-hospital mortality in very elderly hypertensives. J Am Med Dir Assoc 2017, Epub ahead of print.

17 Sarzani R, Spannella F, Giulietti F, Fedecostante M, Giordano P, Gattafoni P, Espinosa E, Busco F, Piccinini G, Dessì-Fulgheri P: NT-proBNP and Its Correlation with In-Hospital Mortality in the Very Elderly without an Admission Diagnosis of Heart Failure. PLoS One 2016;11:e0153759. 
18 Herland K, Akselsen JP, Skjønsberg OH, Bjermer L: How representative are clinical study patients with asthma or COPD for a larger "real life" population of patients with obstructive lung disease? Respir Med 2005;99: 11-19.

19 Sin DD, Man SF: Why are patients with chronic obstructive pulmonary disease at increased risk of cardiovascular diseases? The potential role of systemic inflammation in chronic obstructive pulmonary disease. Circulation 2003;107:1514-1519.

20 Maclay JD, McAllister DA, Mills NL, Paterson FP, Ludlam CA, Drost EM, Newby DE, Macnee W: Vascular dysfunction in chronic obstructive pulmonary disease. Am J Respir Crit Care Med 2009;180:513-520.
21 Wedzicha JA, Banerji D, Chapman KR, Vestbo J, Roche N, Ayers RT, Thach C, Fogel R, Patalano F, Vogelmeier CF; FLAME Investigators: Indacaterol-glycopyrronium versus salmeterol-fluticasone for COPD. N Engl J Med 2016;374:2222-2234.

22 Ficker JH, Rabe KF, Welte T: Role of dual bronchodilators in COPD: a review of the current evidence for indacaterol/glycopyrronium. Pulm Pharmacol Ther 2017;45:19-33.

23 Lahousse L, Verhamme KM, Stricker BH, Brusselle GG: Cardiac effects of current treatments of chronic obstructive pulmonary disease. Lancet Respir Med 2016;4:149-164.

24 Buch P, Friberg J, Scharling H, Lange P, Prescott E: Reduced lung function and risk of atrial fibrillation in the Copenhagen City Heart Study. Eur Respir J 2003;21:1012-1016.
25 D’Urzo, Ferguson GT, van Noord JA, Hirata K, Martin C, Horton R, Lu Y, Banerji D, Overend TA: Efficacy and safety of once-daily NVA237 in patients with moderate-to-severe COPD: the GLOW1 trial. Respir Res 2011;12: 156.

26 Girodet PO, Jasnot JY, Le Gros V, Decuypère L, Cao W, Devouassoux G: Efficacy and safety of indacaterol in patients with chronic obstructive pulmonary disease aged over 65 years: a pooled analysis. Respir Med 2017;128: 92-101.

27 Bateman ED, Ferguson GT, Barnes N, Gallagher N, Green Y, Henley M, Banerji D: Dual bronchodilation with QVA149 versus single bronchodilator therapy: the SHINE study. Eur Respir J 2013;42:1484-1494. 